This document is confidential and is proprietary to the American Chemical Society and its authors. Do not copy or disclose without written permission. If you have received this item in error, notify the sender and delete all copies.

\title{
Iminium Catalysis inside a Self-Assembled Supramolecular Capsule: Scope and Mechanistic Studies
}

\begin{tabular}{|r|l|}
\hline Journal: & Journal of the American Chemical Society \\
\hline Manuscript ID & ja-2017-08976k.R1 \\
\hline Manuscript Type: & Article \\
\hline Date Submitted by the Author: & 01-Nov-2017 \\
\hline Complete List of Authors: & $\begin{array}{l}\text { Braeuer, Thomas; University of Basel, Department of Chemistry } \\
\text { Zhang, Q; University of Basel, Department of Chemistry } \\
\text { Tiefenbacher, Konrad; University of Basel, Department of Chemistry }\end{array}$ \\
\hline
\end{tabular}

SCHOLARONE ${ }^{\text {m }}$

Manuscripts 


\section{Introduction}

The field of intermolecular enantioselective enamine $e^{1}$ and iminium $^{\mathrm{lb}-\mathrm{d}, 2}$ organocatalysis has flourished since the seminal reports in the year 2000 by List $^{3}$ and MacMillan, ${ }^{4}$ respectively. Iminium catalysis is now regularly used for the construction of chiral building blocks via mainly 1,4-addition and cycloaddition; while enamine catalysis is a potent tool for the construction of $\alpha$-functionalized carbonyl compounds. Although these fields were heavily investigated and still receive tremendous attention, efforts to combine these activation modes with supramolecular assemblies have been very limited. The Rebek group investigated a Knoevenagel reaction accelerated by an amine catalyst bound to an open cavitand. ${ }^{5}$ A series of rotaxane-based switchable aminocatalysts were prepared by the Leigh group and used for iminium and enamine catalysis. ${ }^{6}$ Recently, an additional rotaxane-based organocatalyst was reported by the Leung group. ${ }^{7}$ In all of these cases, the supramolecular structure functioned as the amine catalyst itself or entrapped the catalyst in an open cavity. The reactions themselves were still taking place in solution. In other words, the supramolecular structure just modified the catalyst and did not allow entrapping the reactive intermediates. The groups of Raymond and Bergman did encapsulate an iminium species inside a supramolecular container but did not observe conversion. ${ }^{8}$ Recently, our group reported the first example of an iminium catalyzed reaction taking place inside a supramolecular container. ${ }^{9}$ Due to the binding of the reactive iminium species on the inside of the capsule, the enantiomeric excess of the product was increased as compared to the reaction in solution under otherwise identical conditions. We now report the full details concerning this reaction including substrate scope, mechanistic details and also expand the reaction to further nucleophiles.
Catalysis inside self-assembled supramolecular containers is gaining interest in the scientific community. ${ }^{10}$ It offers the potential to observe substrate- and product-selectivities not observed in regular solution experiments and, additionally, could facilitate multicatalyst tandem reactions. ${ }^{11}$ Recent examples included a Kemp elimination, ${ }^{12}$ reductive elimination, ${ }^{13}$ gold catalyzed reactions, ${ }^{14}$ epoxidations, ${ }^{15}$ and an allylic oxidation/Diels-Alder cycloaddition sequence. ${ }^{16}$

Our group ${ }^{9,17}$ and the groups of Scarso and Strukul ${ }^{18}$ have utilized the supramolecular capsule I, first reported by the Atwood group, ${ }^{19}$ successfully as catalyst. Container I self-assembles from six resorcinarene units $\mathbf{1}$ and eight water molecules in non-competitive solvents like chloroform. With an internal volume of approx. $1.4 \mathrm{~nm}^{3}$ it is one of the largest hydrogen bond-based molecular capsules available. ${ }^{20}$ Guest exchange, which is believed to occur via a portal mechanism, is facile. ${ }^{21}$ Cationic molecules, for instance alkyl ammonium ions bind strongly to the cavity of I due to cation- $\pi$ interactions. ${ }^{10,}, 22$ We reported that capsule I acts as a reasonable strong Brønsted acid. ${ }^{17 a}$ This acidity, in combination with the capsule's ability to stabilize cationic intermediates/transition states, is responsible for its catalytic activity. However, in some cases, additional external acid is required. ${ }^{17 e, 18 d} \mathrm{~A}$ very closely related supramolecular assembly is capsule II, which self-assembles from pyrogallolarene units $2 .{ }^{23} \mathrm{We}$ recently reported that capsule II is catalytically inactive for terpene cyclizations, ${ }^{24}$ most likely due to its inability to encapsulate ion pairs. ${ }^{1 \mathrm{e}}$ Its potential for iminium catalysis, however, remained unexplored. 


\section{Enamine Cycle}<smiles>[R]C(F)=CC=O</smiles><smiles>[R]O[C@H]1CC[C@@H]1C</smiles><smiles>O=C1CCCN1</smiles><smiles>[R]/C(F)=C\C1CCCN1O</smiles><smiles>C=CC(C)C</smiles><smiles>CCOCC=CC1CCCN1CCO</smiles>

Figure 2: Cycles for enamine and iminium catalysis.

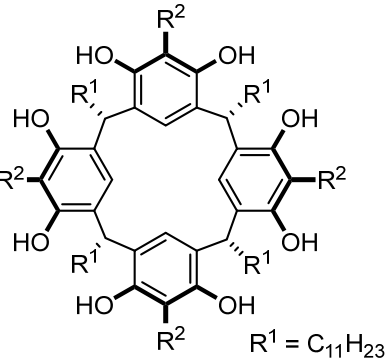

\section{$\stackrel{1}{\left(R^{2}=H\right)}$ \\ $\stackrel{2}{2}\left(\mathrm{R}^{2}=\mathrm{OH}\right)$}

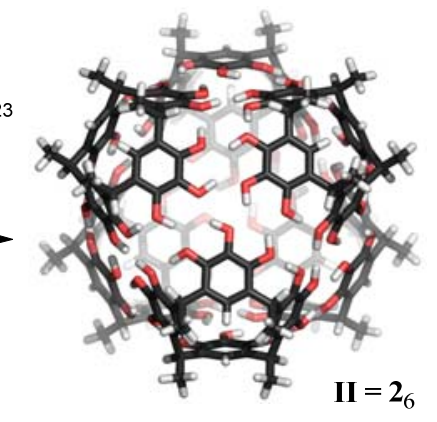

Figure 1: Structures of resorcinarene (1) and pyrogallolarene (2) and their respective self-assembled hexameric capsules I and II.

\section{Results and discussion}

Enamine vs. Iminium catalysis. At the outset of the investigation, we tried to evaluate the potential of enamine and iminium organoenamine catalysis, the reactive species is certainly the enamine, which is in situ formed from the aldehyde substrate and the amine catalyst. Amines and also enamines are only encapsulated in their porms inside capsule $\mathbf{I}{ }^{1 / 2}$ therefore, enamine catalysis will be inhibited inside the container and only take place outside in contrast, the reactive species in iminium catalysis is the charged iminium species that should display a high affinity towards the interior of capsule $I$ due to strong cation- $\pi$ interactions b)<smiles>[R]CC([CH2+])=CC1C(C)=C(C)CC1CO</smiles><smiles>[R]CC=[N+]1CCCC1</smiles><smiles>CC1CCCCC1=O</smiles>

(Fig. 2b). If the in situ formed iminium species is encapsulated fast enough within I, its conversion with a nucleophile might indeed take place inside the restricted environment of the capsule. This might lead to different substrate- and stereoselectivities than observed in a regular solution experiment. To validate these considerations, two competition experiments were initially investigated in the presence of capsule I. We investigated the size selectivity of the enamine-catalyzed addition of propanal (3) to differently sized nitroolefins $\mathbf{4 a}$ and $\mathbf{4 b}$. If the reaction takes place inside the cavity of $\mathbf{I}$, a selectivity towards the smaller addition product would be expected, as the larger nitro olefin $\mathbf{4 b}$ is too large for encapsulation. ${ }^{17 a-}$ ${ }^{c}$ However, even a slight preference for the larger addition product 6b was observed, indicating that the reaction took place outside of the container.

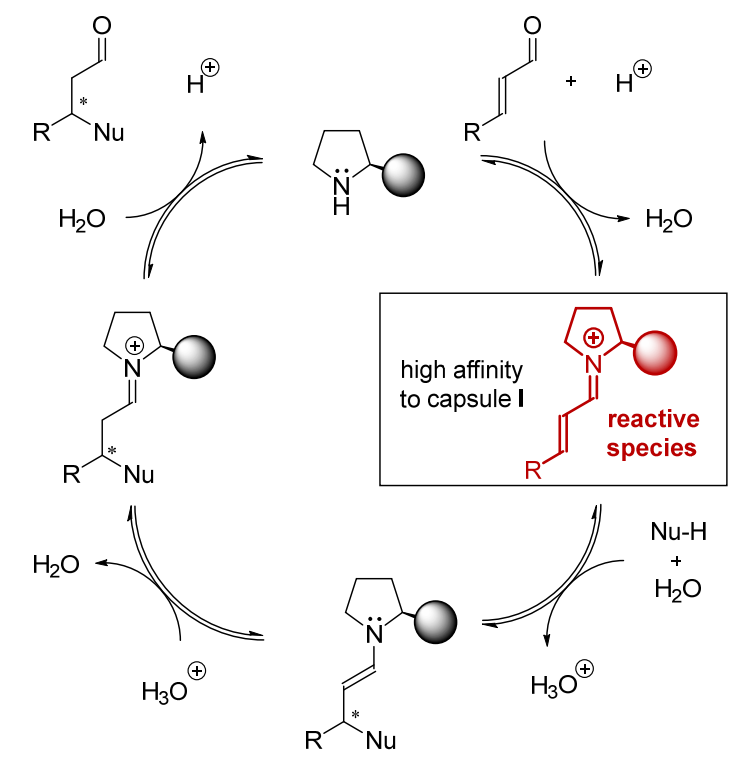


Figure 3: Size selectivity experiments for enamine and iminium ion catalysis in the presence and absence of capsule I.

Without I both addition products are also formed in approx. equal amounts (Fig. 3a). Additionally, no significant difference in the optical purity of product 6a was observed when the reaction was run with $(97 \% e e)$ or without capsule $(98 \% e e)$. As an example for iminium catalysis, the 1,4-reduction of an $\alpha, \beta$-unsaturated aldehyde utilizing Hantzsch ester as a hydride equivalent was utilized (Fig. 3b). Again, two differently sized substrates (trans-2-hexenal (7a) and trans-2-tridecenal $(7 \mathbf{b})$ ) were utilized to detect a potential size selectivity imposed by capsule I. Indeed, a significant selectivity towards the smaller product 9a (10:1.0) was observed in the presence of catalytic amounts of I ( $26 \mathrm{~mol} \%)$. This is in stark contrast to the reaction without capsule under otherwise identical reaction conditions, where even a slight selectivity towards the larger product was detected (1.0:1.2). These initial results confirmed our assumption that indeed iminium catalysis is feasible in the inside of capsule I and that the transiently formed reactive iminium species are encapsulated fast enough to efficiently suppress the background reaction outside in solution. Intrigued by these results, we decided to explore enantioselective iminium catalysis inside the capsule. Since the enantiotopos-differentiating step, the attack of the nucleophile onto the encapsulated iminium ion, would be required to take place inside the densely packed environment of the host, we expected to observe an alteration in enantioselectivity as compared to the solution experiment. Preliminary results confirming this hypothesis were published last year by our group. ${ }^{9}$

The known enantioselective 1,4-reduction of $\beta$-substituted $\alpha, \beta$-unsaturated aldehydes with Hantzsch ester $8 \mathbf{a}$ (1.5 equiv) as a reducing agent was utilized as a starting point in this investigation (Table 1). ${ }^{25}$ In the initial screening, ${ }^{9}$ L-proline (5b, 20 mol\%) was identified as the most promising organocatalyst for this study. Interestingly, in the presence of catalytic amounts of capsule I ( $26 \mathrm{~mol} \%)$, a much higher enantioselectivity $(74 \%$ ee $(S)$ vs. $9 \%$ ee $(S)$; corresponding to a $\Delta e e$ of $65 \%)$ was observed than in a regular solution b) Iminium Ion Catalysis

$$
\begin{aligned}
& \mathrm{C}_{3} \mathrm{H}_{7}=0 \quad 7 a \\
& \mathrm{C}_{10} \mathrm{H}_{21} \\
& =0
\end{aligned}
$$

\begin{tabular}{|c|c|c|}
\hline $\begin{array}{l}\text { Capsule I } \\
\text { present? }\end{array}$ & $9 a$ & $9 b$ \\
\hline yes & 10 & 1.0 \\
\hline no & 1.0 & 1.2 \\
\hline
\end{tabular}

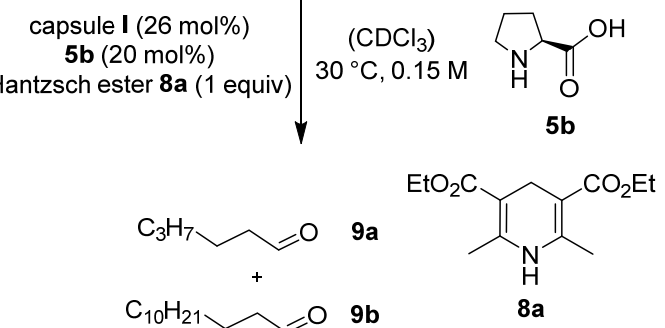

experiment under otherwise identical conditions (Table 1, entries 1-2). The experiment using D-proline delivered, as expected, the opposite result of the experiment using L-proline $(\mathbf{5 b})$ as organocatalyst $(77 \% e e(R))$. The closely related pyrogallolarene capsule II, on the other hand, did not display this modulation effect on the enantioselectivity observed (no $\Delta e e$ was observed; Table 1 , entry 3).

Table 1: Comparison of the resorcinarene I and the pyrogallolarene II capsule in the 1,4-reduction of (E)-3-phenyl-2-butenal (10a).

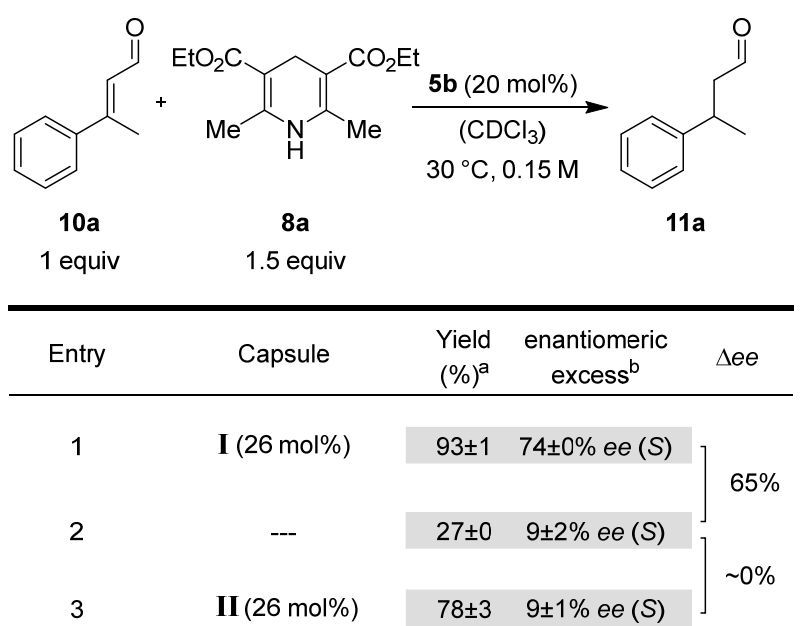

[a] determined by GC analysis; [b] determined by chiral GC analysis.

Control experiments. To learn more about these results, we first aimed at understanding where the reaction takes place. Several control experiments were performed to elucidate the role of capsule I. Separate reactions were run with either a large Hantzsch ester (Table $2, \mathbf{8 b})$, a large organocatalyst $\mathbf{5 c}$ or a large aldehyde $\mathbf{1 0 b}$ 
instead of the respective standard reactants (Table 1). Molecular modeling ${ }^{26}$ indicated that reactions involving one of these enlarged reactants/reagents would not be possible inside the confined environment of $\mathbf{I}$. Therefore, such reactions would have to occur outside in the solution and/or on the outer surface of capsule I. In all these three cases, $\Delta e e$ values well below $\pm 10 \%$ were observed, much lower than the value of $65 \%$ observed under the regular conditions. In an ideal control experiment of this kind, no $\Delta e e$ would be expected. We attribute the small modulating effect observed in these control reactions to a (weak) interaction of the reactive iminium species to the outside of the capsule; this seems likely since it is known that tetraalkyl ammonium ions are able to bind weakly to the outside of capsule $\mathbf{I}^{27}$

Table 2: Performed control experiments involving a large Hantzsch ester $\mathbf{8 b}$, a large catalyst $\mathbf{5 c}$, a large aldehyde $\mathbf{1 0 b}$ and hexamethonium bromide (12).

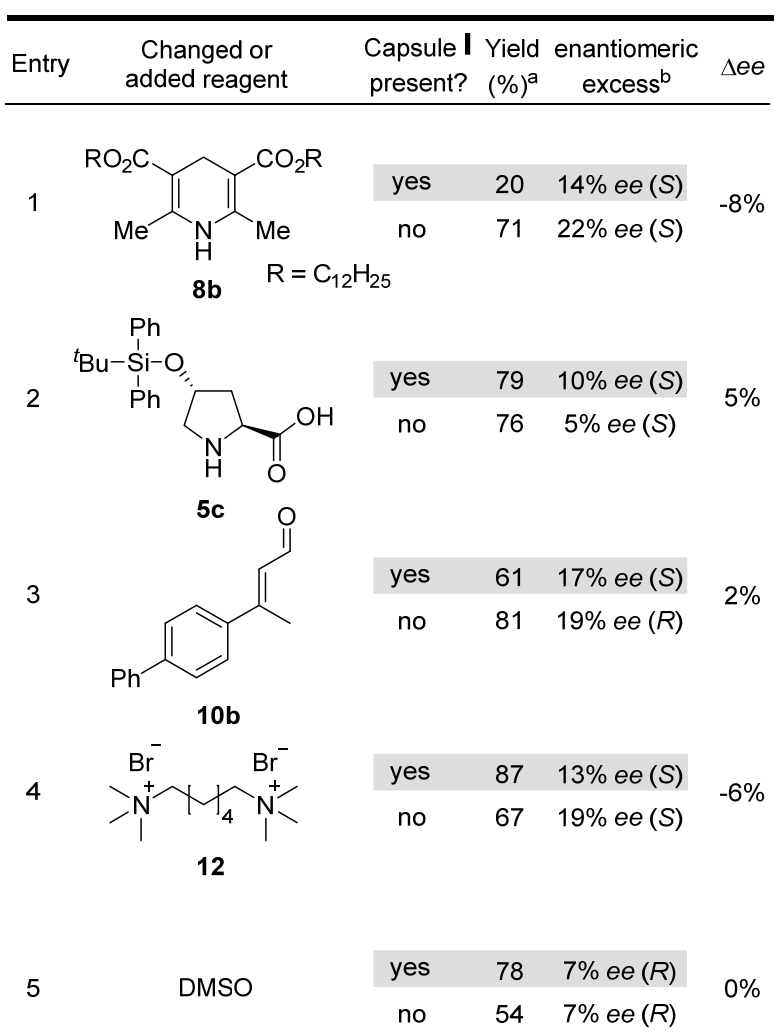

[a] determined by GC analysis; [b] determined by chiral GC analysis.

Additionally, a control experiment was performed in which the cavity of I was blocked by hexamethonium bromide (12), a bis ammonium salt (Table 2, entry 4). In previous publications of our group, we successfully blocked capsule I with tetrabutyl ammonium bromide. In this project, however, the usage of singly charged ammonium salts would not suppress the uptake of the iminium species efficiently. Due to its higher charge, we expected 12 to outcompete the iminium species efficiently. Indeed, this control experiment also resulted in a greatly reduced $\Delta e e$. In another control experiment, we added DMSO to the experiment with capsule. DMSO destroys the hexameric structure of capsule I by interrupting the hydrogen bond network. Also in this control experiment no modulation of enantiomeric excess is observed ( $\Delta e e$ of $0 \%)$ These five control experiments provide convincing evidence that the strong modulation of enantiomeric excess indeed stems from an encapsulation effect inside host $\mathbf{I}$.

Source of ee-modulation. The modulation of enantioselectivity inside $\mathbf{I}$ is even more intriguing when taking into account that the building blocks of capsule I, resorcinarene $\mathbf{I}$ (Fig. 1) and water, are achiral. This means that no additional chiral information is added to the experiment. The different enantioselectivity observed within I may stem from altered reactivities of the respective $E$ - and $Z$-alkene isomers of the iminium ion (Fig. 4a). It was reported by MacMillan that both alkene isomers of aldehyde 10a are converted to the same product enantiomer. ${ }^{25 c}$ This stereoconvergence is attributed to a rapid iminium-catalyzed $Z \rightarrow E$ isomerization and a selective hydride delivery to the $E$-isomer. We, therefore, decided to investigate the isomerization in the presence of the supramolecular system in detail. In solution, when starting from the $E$-isomer, the unreacted starting material 10a displayed an $E / Z$ ratio of 1.95 after $8 \mathrm{~h}$ under the standard reaction conditions (Table 3, entry 1 without capsule). A similar ratio was reached after $8 \mathrm{~h}$ when starting from the $Z$-isomer (entry 2 without capsule). This indicates that an equilibrium distribution of approx. 1.8 between the $E$ - and $Z$ isomer is reached in the solution experiment (for details see SI). Interestingly, the capsule experiments displayed contrasting results. In both cases, the purity of the alkene isomer added was retained rather efficiently. After $8 \mathrm{~h}$, the ratios were still 8.16 and 0.09 , respectively. Nevertheless, also in the capsule experiments a stereoconvergence of the final product was observed, indicating that an isomerization took place after iminium formation but before hydride addition in the case of the $Z$-alkene isomer. This likely indicates that once a $Z$-iminium species is formed and encapsulated, it is isomerized to the $E$-iminium species and predominantly converted to the product without hydrolysis in between, thereby retaining the substrate isomer ratio in solution. In a regular solution experiment, however, the formed iminium is predominantly hydrolyzed again after isomerization, resulting in the fast equilibration of the added alkene isomers. This interpretation of the results is also in line with observations with a different supramolecular host which is able to protect iminium ions from hydrolysis. ${ }^{8}$ Therefore, altered reactivities of the respective $E$ - and $Z$-alkene isomers of the iminium ion inside the capsule cannot explain the modulation of ee observed.

An alternative explanation for the observed modulation of enantioselectivity inside I may involve the chirality of I. Although, as stated before, the building blocks of I are achiral, the assembly of I itself is chiral due to the twisted arrangement of the subunits (Fig. 1). ${ }^{19 a}$ Nevertheless, the capsule is present as racemate. It was recently shown that encapsulated chiral tertiary amines (good guests due to protonation by the capsule $\mathbf{I})^{17 \mathrm{a}}$ induce optical activity onto the capsule itself. ${ }^{28}$ It is likely that the chiral iminium ion formed during iminium catalysis would impose a similar induction onto I. However, the weak chiral field produced by the slight twists of the capsule components is not the most likely source of the effect observed. Also the pronounced differences in ee-modulation for very similar substrates (vide infra, Table 4) is supporting another mechanism. It is more likely that the modulation stems from a binding effect. 
Our hypothesis is that the iminium preferentially binds to the inner walls of capsule I from the less hindered side (anti to the carboxylic acid of proline, Fig. 4b). This arrangement then facilitates the attack of the nucleophile from the top face (syn to the carboxylic acid), which preferentially produces the $(S)$-product in case of $\mathrm{L}-$ proline. This mechanism is in accordance with the selectivities observed and with our current understanding of the system.

In any case, why is the modulation effect not observed with capsule II? Recent findings from our group indicate that capsule II does not encapsulate ion pairs due to the absent stabilization of anions within its cavity. ${ }^{24}$ Since the iminium ion formed is present as an ion pair in an apolar solvent like chloroform, it is likely that indeed failure of uptake into its cavity is the reason for the lack of modulation with II.

Aldehyde substrate scope. Next, the aldehyde substrate scope was investigated in detail. The cyclohexyl derivative 10c showed a reduced $\Delta e e$ of only $26 \%$, which might indicate that the aromatic moiety of the aldehyde plays an important role in binding of the iminium species inside I via $\pi-\pi$ interactions. Subsequently, three methyl derivatives of $(E)$-3-phenyl-2-butenal (10a) were investigated. Interestingly, the results differed dramatically: The para-derivative (10d, $\Delta e e=9 \%)$ and $m e t a$-derivative $(10 \mathrm{e}, \Delta e e=41 \%)$ produced only low to modest selectivity differences inside the capsule. However, the ortho-derivative (10f) displayed a very high $\Delta e e$ of $92 \%$. These dramatic differences for the methyl derivatives 10df support our hypothesis that the binding of the iminium species to the capsule walls is responsible for the selectivity increase. In the case of $10 f$, however, only a yield of $12 \%$ was obtained. To examine if the ortho-position generally delivers poor yields, we tested the ortho-methoxy derivative $10 \mathrm{~g}$. To our delight a high yield of $96 \%$ and a noteworthy $\Delta e e$ of $69 \%$ were obtained. Further ortho-substituted derivatives were investigated: All halogenated substrates 10h-j displayed high $\Delta e e$ values, indicating that indeed ortho-substituted derivative in general display better selectivities inside the capsule. The decrease in yield and conversion in the series $10 \mathrm{~h}$ to $10 \mathrm{j}$ indicates that a large ortho-substituent is slowing down the reaction considerably. The smaller fluoro-substituted aldehyde $\mathbf{1 0 h}$ produced a good yield of $76 \%$, whereas the much larger bromosubstituted aldehyde $10 j$ formed the respective product $11 \mathbf{j}$ in only $14 \%$. The even larger nitro-compound $10 \mathrm{k}$ also followed the observed trend.

Mechanistic studies. To gain a better insight into the 1,4-reduction inside capsule I at hand, mechanistic studies were performed by using the initial rate method. Under the standard reaction conditions, pseudo first order consumption of the $\alpha, \beta$-unsaturated aldehyde was observed (Fig. 4a). Additionally, the activation parameters 
were measured by performing the reaction at different temperatures (Fig. $4 \mathrm{~b}$ ).

Table 4: Results of the iminium catalyzed 1,4-reduction of different aldehydes 10 utilizing proline $(\mathbf{5 b})$ as catalyst.

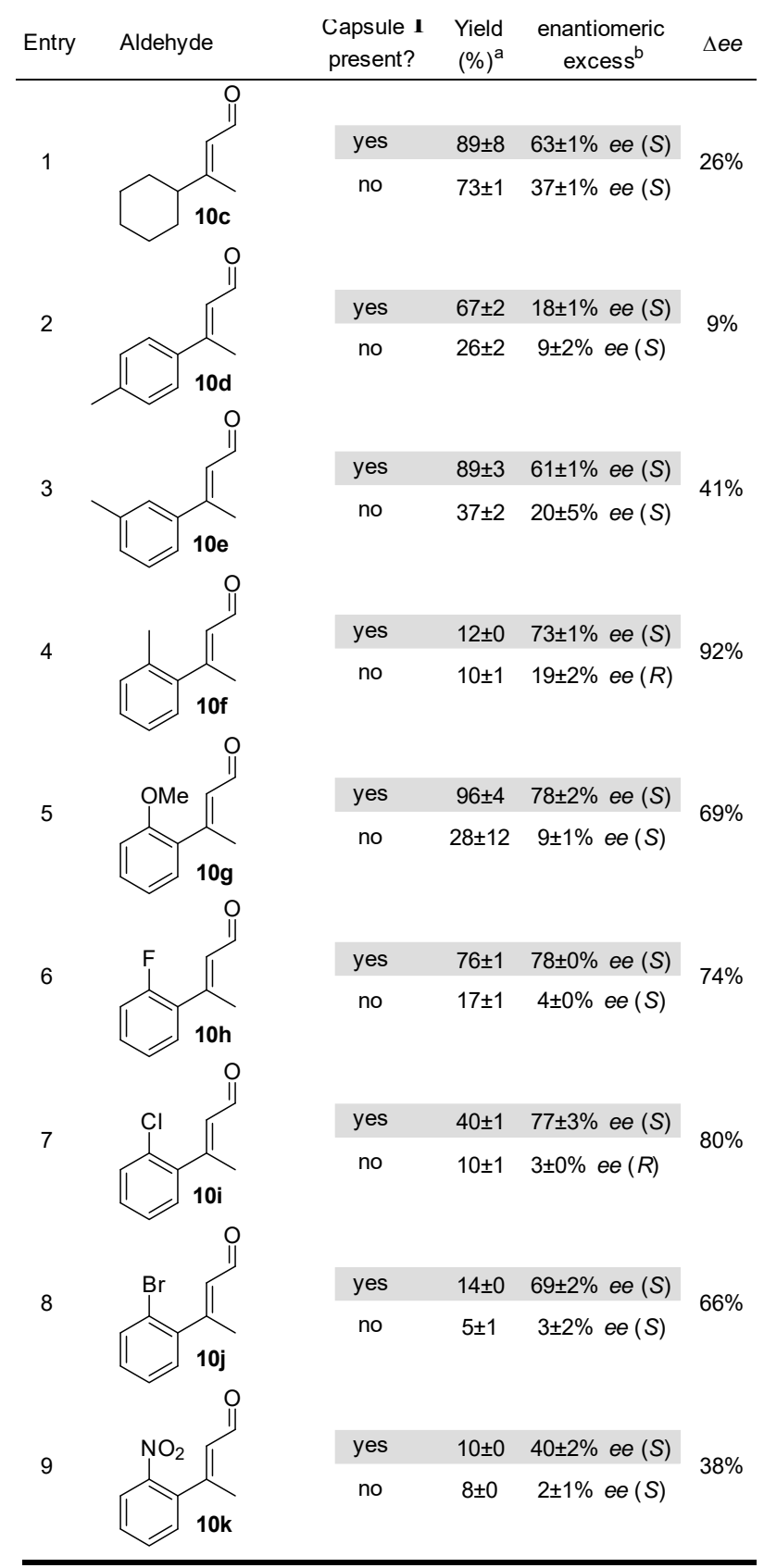

[a] determined by GC analysis; [b] determined by chiral GC analysis.

The obtained parameters for the capsule-mediated 1,4-reduction reaction are $\Delta H^{\ddagger}=21.10 \pm 0.16 \mathrm{kcal} / \mathrm{mol}, \Delta S^{ \pm}=-9.57 \pm 0.49 \mathrm{~J} / \mathrm{mol}$ and $\Delta G^{\neq}=24.00 \pm 0.02 \mathrm{kcal} / \mathrm{mol}$. The negative entropy of activation observed may indicate that the bimolecular hydride transfer is the rate determining step of the reaction inside capsule I. Additional evidence was sought by investigating the kinetic isotope effect for the hydride transfer. The known $d_{2}$-Hantzsch ester $\mathbf{8} \mathbf{c}^{29}$ (Fig. 6) was synthesized from $d_{2}$-paraformaldehyde utilizing the classical Hantzsch ester synthesis. The experiments utilizing the regular and deuterated Hantzsch ester $\mathbf{8 a}$ and $\mathbf{8 c}$, respectively, were run in triplicate. A primary kinetic isotope effect of $k_{\mathrm{H}} / k_{\mathrm{D}}=$ $1.90 \pm 0.05$ was observed, providing strong evidence that indeed the hydride transfer is the rate determining step.

(a)
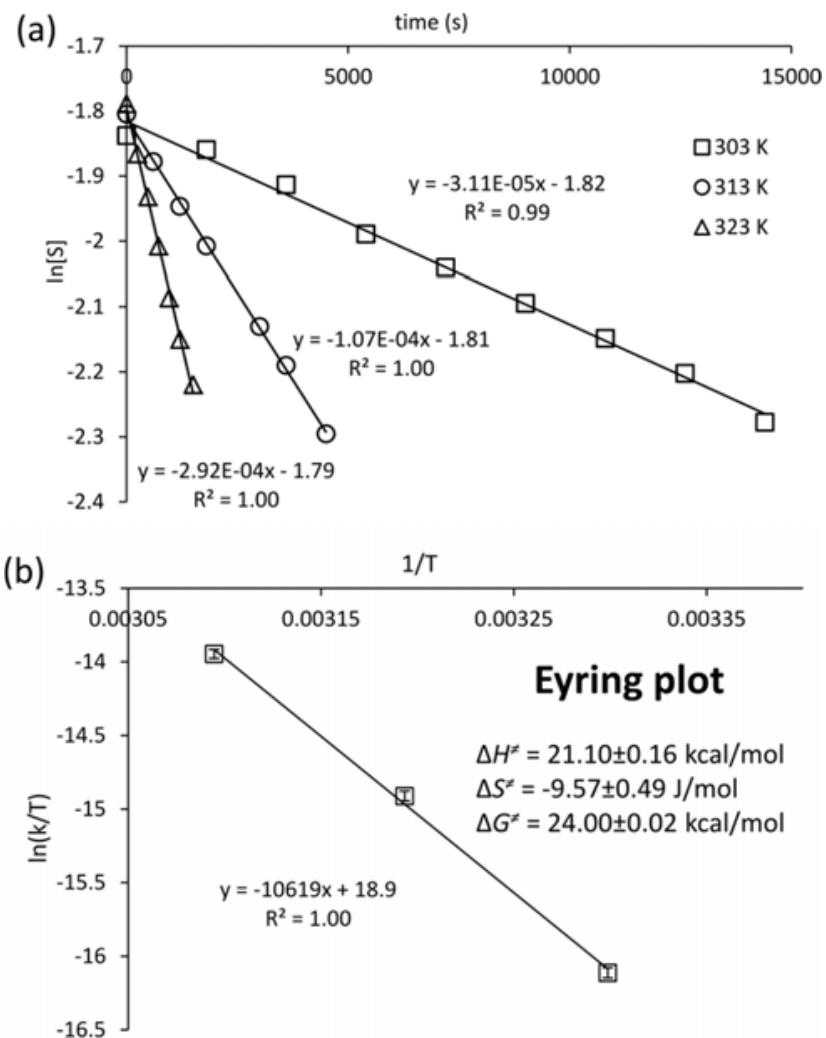

Figure 5: (a) Initial rates at $303 \mathrm{~K}, 313 \mathrm{~K}$ and $323 \mathrm{~K}$; (b) Eyring plot.

Alternative hydride sources. Since transfer of the hydride is the rate determining step, changing the hydride source potentially has a strong impact on the selectivities observed. Therefore, we investigated alternative hydride sources. Our interest turned to benzothiazolidines, which were shown to reduce imines in a phosphoric acid-catalyzed transfer hydrogenation. ${ }^{30}$

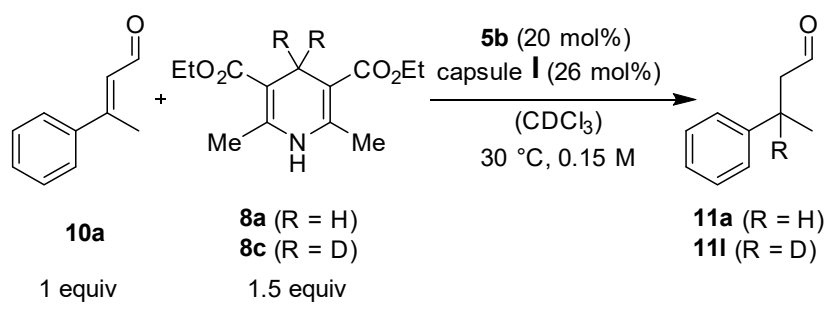

kinetic isotope effect : $k_{H} / k_{D}=1.90 \pm 0.05$

Figure 6: Kinetic isotope effect of the examined 1,4-reduction. 
Table 5: Results of the iminium catalyzed 1,4-reduction utilizing different benzothiazolidines 13.

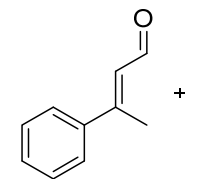<smiles>[R]C1Nc2ccccc2S1</smiles><smiles>CC(CCO)c1ccccc1</smiles>

$10 \mathrm{a}$ 13 $11 \mathrm{a}$

\begin{tabular}{|c|c|c|c|c|c|c|}
\hline & $5 d$ & $5 e$ & & $5 f$ & $5 \mathrm{~g}$ & \\
\hline Entry & Hydride donor & Catalyst & $\begin{array}{l}\text { Capsule I } \\
\text { present? }\end{array}$ & $\begin{array}{l}\text { Yield } \\
(\%)^{a}\end{array}$ & $\begin{array}{c}\text { enantiomeric } \\
\text { excess }^{b}\end{array}$ & $\Delta e e$ \\
\hline \multirow{2}{*}{$1^{\mathrm{c}}$} & & \multirow{2}{*}{$5 b$} & yes & $25 \pm 2$ & $78 \pm 1 \%$ ee $(R)$ & \multirow{2}{*}{ n.d. } \\
\hline & & & no & $<1$ & n.d. & \\
\hline \multirow{2}{*}{$2^{\mathrm{C}}$} & & \multirow{2}{*}{$5 d$} & yes & 5 & $3 \%$ ee $(R)$ & \multirow{2}{*}{$-1 \%$} \\
\hline & & & no & 5 & $2 \%$ ee $(R)$ & \\
\hline \multirow{2}{*}{$3^{c}$} & $\mathrm{R}=$ Phenyl & \multirow{2}{*}{$5 e$} & yes & 9 & $20 \%$ ee $(R)$ & \multirow{2}{*}{$-18 \%$} \\
\hline & $13 a$ & & no & 5 & $2 \%$ ee $(R)$ & \\
\hline \multirow{2}{*}{$4^{d}$} & & \multirow{2}{*}{$5 f$} & yes & $43 \pm 0$ & $73 \pm 1 \%$ ee $(R)$ & \multirow{2}{*}{$-73 \%$} \\
\hline & & & no & $21 \pm 0$ & $0 \pm 0 \%$ ee & \\
\hline \multirow{2}{*}{$5^{d}$} & & \multirow{2}{*}{$5 \mathrm{~g}$} & yes & $33 \pm 1$ & $28 \pm 6 \%$ ee $(S)$ & \multirow{2}{*}{$47 \%$} \\
\hline & & & no & $19 \pm 8$ & $19 \pm 3 \%$ ee $(R)$ & \\
\hline \multirow{2}{*}{$6^{d}$} & & \multirow{2}{*}{$5 f$} & yes & 43 & $67 \%$ ee $(S)$ & \multirow{2}{*}{$67 \%$} \\
\hline & $\mathrm{R}=$ Methyl & & no & 17 & $0 \%$ ee & \\
\hline \multirow{3}{*}{$7^{d}$} & $13 b$ & & & & & \\
\hline & & \multirow{2}{*}{$5 \mathrm{~g}$} & yes & 24 & $12 \%$ ee $(S)$ & \multirow{2}{*}{$18 \%$} \\
\hline & & & no & 12 & $6 \%$ ee $(R)$ & \\
\hline \multirow{2}{*}{$8^{d}$} & & \multirow{2}{*}{$5 f$} & yes & $3 \pm 0$ & $25 \pm 7 \%$ ee $(S)$ & \multirow{2}{*}{$26 \%$} \\
\hline & $\mathrm{R}=$ Naphthyl & & no & $15 \pm 3$ & $1 \pm 0 \%$ ee $(R)$ & \\
\hline \multirow{2}{*}{$9^{d}$} & $13 c$ & \multirow{2}{*}{$5 g$} & yes & $2 \pm 0$ & $24 \pm 4 \%$ ee $(S)$ & \multirow{2}{*}{$40 \%$} \\
\hline & & & no & $18 \pm 4$ & $16 \pm 1 \%$ ee $(R)$ & \\
\hline
\end{tabular}

[a] determined by GC analysis; [b] determined by chiral GC analysis; [c] 1.5 equiv of reducing agent and concentration of $0.15 \mathrm{M}$; [d] 1 equiv of reducing agent and concentration of $0.075 \mathrm{M}$.

The phenyl- (13a), methyl- (13b) and naphthyl- (13c) derivatives of this class of reducing agents were investigated (Table 5). As with Hantzsch ester $\mathbf{8 a}$ as hydride donor, L-proline (5b) displayed good enantioselectivity in the presence of capsule $(78 \% R)$ with benzothiazolidine 13a. However, the other enantiomer is formed! To rule out mistakes, the absolute configuration of L-proline was checked by measuring the optical rotation. Additionally, the experiments were repeated in triplicate, confirming this surprising result (entry 1, Table 5). Unfortunately, and although starting material was converted, no $\Delta e e$ value could be determined since the corresponding solution experiment did not yield the desired product $11 \mathrm{a}$ at all. In general, the yields using benzothiazolidines as reducing agents were only low to modest, although the conversion of the starting material was good. Investigations revealed that the starting material (the $\alpha, \beta$-unsaturated aldehyde) as well as the product aldehyde underwent trans-N,S-acetalization with the benzothiazolidine (see SI-Fig. S14 - S16). Although these side reactions unfortunately reduced the yield, the results obtained are, in our opinion, nevertheless of high conceptual interest. When utilizing proline derivative $\mathbf{5 d}$, a $\Delta e e$ value near $0 \%$ was observed with benzothiazolidine 13a. Like in the case of $\mathrm{L}$-proline, a preference towards the $R$ enantiomer was also observed with proline amide $5 \mathbf{e}(\Delta e e$ of $-18 \%)$ and L-thioproline (5f, $\Delta e e$ of $-73 \%$ ) as organocatalysts. This is the first time we observed selectivity towards the $R$-enantiomer inside the capsule when utilizing the $S$-configured secondary amines utilized for this study. What causes this tendency towards the $R$-enantiomer? There might be additional $\pi-\pi$ interactions of the aromatic benzothiazolidine 13a with the capsule walls or, alternatively, cation- $\pi$ interactions between the iminium ion and the hydride 
source. Such interactions could override the proposed binding of the iminium species (Fig. 4b) and, therefore, lead to opposite enantioselectivites. With proline tetrazole $\mathbf{5 g}$, which features an electron poor aromatic surface, this effect is not detected ( $\Delta e e$ of $47 \%)$. To learn more about these surprising observations, catalysts $\mathbf{5} \mathbf{f}$ and $\mathbf{5 g}$ were further investigated using other benzothiazolidines. First benzothiazolidine $\mathbf{1 3 b}$, which carries a methyl group instead of a phenyl substituent was tested. With L-thioproline (5f) as catalyst and $\mathbf{1 3 b}$ as hydride donor, a high $\Delta e e$ of $67 \%$ is observed, whereas $18 \%$ are obtained with $\mathbf{5 g}$. In both cases the expected $(S)$-product is formed preferentially inside I again. This supports the notion that indeed the additional phenyl ring in reducing agent 13a caused the observed preference for the $R$-configured product inside the capsule, since the methyl derivative $\mathbf{1 3 b}$ did not display this effect. When using the larger naphthyl-benzothiazolidine 13c, the size limit of capsule $\mathbf{I}$ is reached and only very low yields of product are observed in these cases. The investigations into the benzothiazolidine revealed how subtle non-covalent interactions between the reactants and the capsule can lead to complete changes in the optical activity of the reduction product. Although these modulation effects are not predictable at this stage, we believe that further investigations with additional supramolecular structures are justified. The increased enantiomeric excess observed within capsule I will be especially helpful in examples of iminium catalysis where no satisfactory enantiocontrol can be achieved with regular solution chemistry so far. ${ }^{31}$

\section{Conclusion}

In summary, detailed investigations into the first example of iminium catalysis inside a supramolecular host are described. The differences in influencing enamine and iminium catalyzed reactions inside capsule I were explored. Several control experiments were performed and provided strong evidence that the modulation of enantiomeric excess of the reaction product indeed stems from a reaction on the inside of capsule $\mathbf{I}$. The origin of the increased enantioselectivity in the capsule was explored. Failure of the related capsule II to provide a similar effect, likely stems from its inability to encapsulate ion pairs. Furthermore, the substrate scope of the reduction with Hantzsch ester was explored. The best enantioselectivities were observed with ortho-substituted derivatives. Kinetic investigations, as well as the kinetic isotope effect measured confirmed that the hydride delivery to the substrate is the rate-determining step inside the capsule. Investigations into benzothiazolidines as alternative hydride sources revealed an unexpected substitution effect of the hydride source itself. The research presented confirms that the non-covalent combination of supramolecular hosts with iminium catalysis is opening up new exciting possibilities to increase enantioselectivity in challenging reactions.

\section{ASSOCIATED CONTENT}

Supporting Information. This material is available free of charge via the Internet at http://pubs.acs.org.

\section{AUTHOR INFORMATION}

\section{Corresponding Author}

konrad.tiefenbacher@unibas.ch / tkonrad@ethz.ch

\section{Notes}

The authors declare no competing financial interest.

\section{ACKNOWLEDGMENT}

This work was supported by funding from the Swiss National Science Foundation as part of the NCCR Molecular Systems Engineering and the Bayerische Akademie der Wissenschaften (Junges Kolleg). T. M. B. thanks the National Research Fund, Luxembourg for an AFR fellowship. We thank Dr. Johannes Richers for graphical design.

\section{REFERENCES}

1. (a) Mukherjee, S.; Yang, J. W.; Hoffmann, S.; List, B., Chem. Rev. 2007, 107, 5471-5569; (b) Melchiorre, P.; Marigo, M.; Carlone, A.; Bartoli, G., Angew. Chem. Int. Ed. 2008, 47, 6138-6171; (c) Bertelsen, S.; Jørgensen, K. A., Chem. Soc. Rev. 2009, 38, 2178-2189; (d) Matos Paz, B.; Jiang, H.; Jørgensen, K. A., Chem. Eur. J. 2015, 21, 1846-1853.

2. (a) Erkkilä, A.; Majander, I.; Pihko, P. M., Chem. Rev. 2007, 107, 5416-5470; (b) Mahlau, M.; List, B., Angew. Chem. Int. Ed. 2013, 52, 518-533.

3. List, B.; Lerner, R. A.; Barbas, C. F., J. Am. Chem. Soc. 2000, 122, 2395-2396.

4. Ahrendt, K. A.; Borths, C. J.; MacMillan, D. W. C., J. Am. Chem. Soc. 2000, 122, 4243-4244.

5. Berryman, O. B.; Sather, A. C.; Lledó, A.; Rebek, J., Angew. Chem. Int. Ed. $2011,50,9400-9403$.

6. (a) Blanco, V.; Carlone, A.; Hänni, K. D.; Leigh, D. A.; Lewandowski, B., Angew. Chem. Int. Ed. 2012, 51, 5166-5169; (b) Blanco, V.; Leigh, D. A.; Lewandowska, U.; Lewandowski, B.; Marcos, V., J. Am. Chem. Soc. 2014, 136, 15775-15780; (c) Blanco, V.; Leigh, D. A.; Marcos, V.; Morales-Serna, J. A.; Nussbaumer, A. L., J. Am. Chem. Soc. 2014, 136, 4905-4908; (d) Beswick, J.; Blanco, V.; De Bo, G.; Leigh, D. A.; Lewandowska, U.; Lewandowski, B.; Mishiro, K., Chem. Sci. 2015, 6, 140-143; (e) Cakmak, Y.; Erbas-Cakmak, S.; Leigh, D. A., J. Am. Chem. Soc. 2016, 138, 1749-1751; (f) Eichstaedt, K.; JaramilloGarcia, J.; Leigh, D. A.; Marcos, V.; Pisano, S.; Singleton, T. A., J. Am. Chem. Soc. 2017, 139, 9376-9381.

7. Kwan, C.-S.; Chan, A. S. C.; Leung, K. C.-F., Org. Lett. 2016, 18, 976979.

8. Dong, V. M.; Fiedler, D.; Carl, B.; Bergman, R. G.; Raymond, K. N., J. Am. Chem. Soc. 2006, 128, 14464-14465.

9. Bräuer, T. M.; Zhang, Q.; Tiefenbacher, K., Angew. Chem. Int. Ed. 2016, 55, 7698-7701.

10. (a) Vriezema, D. M.; Comellas Aragonès, M.; Elemans, J. A. A. W.; Cornelissen, J.J. L. M.; Rowan, A. E.; Nolte, R. J. M., Chem. Rev. 2005, 105, 1445-1490; (b) Koblenz, T. S.; Wassenaar, J.; Reek, J. N. H., Chem. Soc. Rev. 2008, 37, 247-262; (c) Yoshizawa, M.; Klosterman, J. K.; Fujita, M., Angew. Chem. Int. Ed. 2009, 48, 3418-3438; (d) Meeuwissen, J.; Reek, J. N. H., Nat. Chem. 2010, 2, 615-621; (e) Marchetti, L.; Levine, M., ACS Catal. 2011, 1, 1090-1118; (f) Wiester, M. J.; Ulmann, P. A.; Mirkin, C. A., Angew. Chem. Int. Ed. 2011, 50, 114-137; (g) Raynal, M.; Ballester, P.; Vidal-Ferran, A.; van Leeuwen, P. W. N. M., Chem. Soc. Rev. 2014, 43, 1734-1787; (h) Brown, C. J.; Toste, F. D.; Bergman, R. G.; Raymond, K. N., Chem. Rev. 2015, 115, 3012-3035; (i) Leenders, S. H. A. M.; Gramage-Doria, R.; de Bruin, B.; Reek, J. N. H., Chem. Soc. Rev. 2015, 44, 433-448; (j) Zarra, S.; Wood, D. M.; Roberts, D. A.; Nitschke, J. R., Chem. Soc. Rev. 2015, 44, 419-432; (k) Catti, L.; Zhang, Q.; Tiefenbacher, K., Synthesis 2016, 48, 313-328; (1) Otte, M., ACS Catal. 2016, 6, 64916510.

11. Catti, L.; Zhang, Q.; Tiefenbacher, K., Chem. Eur. J. 2016, 22, 9060 9066.

12. Cullen, W.; Misuraca, M. C.; Hunter, C. A.; Williams, N. H.; Ward, M. D., Nat. Chem. 2016, 8, 231-236. 
13. Levin, M. D.; Kaphan, D. M.; Hong, C. M.; Bergman, R. G.; Raymond, K. N.; Toste, F. D., J. Am. Chem. Soc. 2016, 138, 9682-9693.

14. (a) Jans, A. C. H.; Gómez-Suárez, A.; Nolan, S. P.; Reek, J. N. H., Chem. Eur. J. 2016, 22, 14836-14839; (b) Wang, Q.-Q.; Gonell, S.; Leenders, S. H. A. M.; Dürr, M.; Ivanović-Burmazović, I.; Reek, J. N. H., Nat. Chem. 2016, 8, 225-230.

15. Kuijpers, P. F.; Otte, M.; Dürr, M.; Ivanović-Burmazović, I.; Reek, J. N. H.; de Bruin, B., ACS Catal. 2016, 6, 3106-3112.

16. Ueda, Y.; Ito, H.; Fujita, D.; Fujita, M., J. Am. Chem. Soc. 2017, 139, 6090-6093.

17. (a) Zhang, Q.; Tiefenbacher, K., J. Am. Chem. Soc. 2013, 135, 1621316219; (b) Catti, L.; Tiefenbacher, K., Chem. Commun. 2015, 51, 892-894; (c) Zhang, Q.; Tiefenbacher, K., Nat. Chem. 2015, 7, 197202; (d) Catti, L.; Pöthig, A.; Tiefenbacher, K., Adv. Synth. Catal. 2017, 359, 1331-1338; (e) Zhang, Q.; Catti, L.; Pleiss, J.; Tiefenbacher, K., J. Am. Chem. Soc. 2017, 139, 11482-11492.

18. (a) Bianchini, G.; La Sorella, G.; Canever, N.; Scarso, A.; Strukul, G., Chem. Commun. 2013, 49, 5322-5324; (b) Giust, S.; La Sorella, G.; Sperni, L.; Fabris, F.; Strukul, G.; Scarso, A., Asian J. Org. Chem. 2015, 4, 217-220; (c) La Sorella, G.; Sperni, L.; Strukul, G.; Scarso, A., ChemCatChem 2015, 7, 291-296; (d) La Sorella, G.; Sperni, L.; Ballester, P.; Strukul, G.; Scarso, A., Catal. Sci. Technol. 2016, 6, 60316036; (e) La Sorella, G.; Sperni, L.; Strukul, G.; Scarso, A., Adv. Synth. Catal. 2016, 358, 3443 -3449; (f) Caneva, T.; Sperni, L.; Strukul, G.; Scarso, A., RSC Adv. 2016, 6, 83505-83509.

19. (a) MacGillivray, L. R.; Atwood, J. L., Nature 1997, 389, 469-472; (b) Avram, L.; Cohen, Y., J. Am. Chem. Soc. 2002, 124, 15148-15149; (c) Avram, L.; Cohen, Y.; Rebek, J., Chem. Commun. 2011, 47, 53685375 .

20. Beaudoin, D.; Rominger, F.; Mastalerz, M., Angew. Chem. Int. Ed. 2016, 55, 15599-15603.

21. Yamanaka, M.; Shivanyuk, A.; Rebek, J., J. Am. Chem. Soc. 2004, 126, 2939-2943.

22. Shivanyuk, A.; Rebek, J., Proc. Natl. Acad. Sci. U.S.A. 2001, 98, 76627665 .

23. for pioneering work see: (a) Gerkensmeier, T.; Iwanek, W.; Agena, C.; Frohlich, R.; Kotila, S.; Nather, C.; Mattay, J., Eur. J. Org. Chem. 1999, 2257-2262; (b) Atwood, J. L.; Barbour, L. J.; Jerga, A., Chem. Commun. 2001, 0, 2376-2377; (c) Shivanyuk, A.; Rebek, J., Chem. Commun. 2001, 2374-2375; (d) Atwood, J. L.; Barbour, L. J.; Jerga, A., Proc. Natl. Acad. Sci. U.S.A. 2002, 99, 4837-4841; (e) Avram, L.; Cohen, Y., Org. Lett. 2003, 5, 3329-3332; (f) Avram, L.; Cohen, Y., J. Am. Chem. Soc. 2003, 125, 16180-16181; (g) Shivanyuk, A.; Friese, J. C.; Döring, S.; Rebek, J., J. Org. Chem. 2003, 68, 6489-6496; (h) Avram, L.; Cohen, Y., J. Am. Chem. Soc. 2004, 126, 11556-11563; for recent studies see: (i) Guralnik, V.; Avram, L.; Cohen, Y., Org. Lett. 2014, 16, 5592-5595; (j) Avram, L.; Goldbourt, A.; Cohen, Y., Angew. Chem. Int. Ed. 2016, 55, 904-907; (k) Yariv-Shoushan, S.; Cohen, Y., Org. Lett. 2016, 18, 936-939.

24. Zhang, Q.; Catti, L.; Kaila, V. R. I.; Tiefenbacher, K., Chem. Sci. 2017, 8, 1653-1657.

25. (a) Yang, J. W.; Hechavarria Fonseca, M. T.; List, B., Angew. Chem. Int. Ed. 2004, 43, 6660-6662; (b) Yang, J. W.; Hechavarria Fonseca, M. T.; Vignola, N.; List, B., Angew. Chem. Int. Ed. 2005, 44, 108-110; (c) Ouellet, S. G.; Tuttle, J. B.; MacMillan, D. W. C., J. Am. Chem. Soc. 2005, 127, 32-33.

26. Modelling was perfomed with Spartan'14 Wavefunction Inc. Irvine, C.

27. Slovak, S.; Cohen, Y., Supramol. Chem. 2010, 22, 803-807.

28. Pollok, C. H.; Zhang, Q.; Tiefenbacher, K.; Merten, C., ChemPhysChem 2017, 18, 1987-1991.

29. (a) Norcross, B. E.; Klinedinst, P. E.; Westheimer, F. H., J. Am. Chem. Soc. 1962, 84, 797-802; (b) Stockinger, S.; Troendlin, J.; Rominger, F.; Trapp, O., Adv. Synth. Catal. 2015, 357, 3513-3520.

30. (a) Zhu, C.; Akiyama, T., Org. Lett. 2009, 11, 4180-4183; (b) Zhu, C.; Akiyama, T., Adv. Synth. Catal. 2010, 352, 1846-1850; (c)
Henseler, A.; Kato, M.; Mori, K.; Akiyama, T., Angew. Chem. Int. Ed. $2011,50,8180-8183$.

31. for a recent example see: Kaldre, D.; Gleason, J. L., Angew. Chem. Int. Ed. 2016, 55, 11557-11561. 
SYNOPSIS TOC

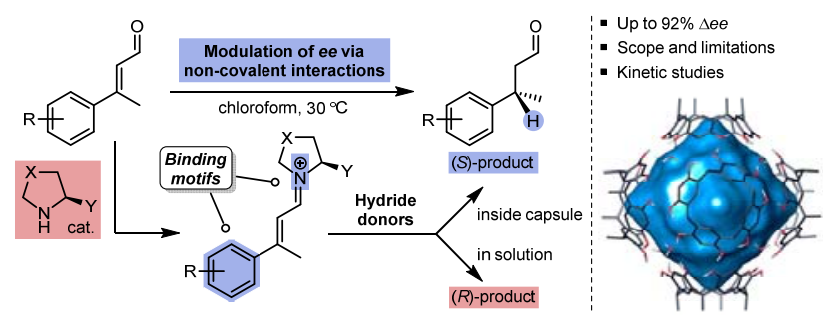

